\title{
Choroidal neovascularization secondary to Best's vitelliform macular dystrophy in two siblings of a Malay family
}

This article was published in the following Dove Press journal:

Clinical Ophthalmology

12 March 2014

Number of times this article has been viewed

\author{
Koh Alisa-Victoria' \\ Tan Jin-Poi' \\ Ismail Shatriah' \\ Embong Zunaina' \\ Nor Fariza Ngah² \\ 'Department of Ophthalmology, \\ School of Medical Sciences, \\ Universiti Sains Malaysia, Kubang \\ Kerian, Kelantan, ${ }^{2}$ Department of \\ Ophthalmology, Hospital Selayang, \\ Lebuhraya Selayang-Kepong, Batu \\ Caves, Selangor, Malaysia
}

Correspondence: Ismail Shatriah Department of Ophthalmology, School of Medical Sciences, Universiti Sains Malaysia, Kubang Kerian, Kelantan 16150, Malaysia Email shatriah@kck.usm.my

\begin{abstract}
Best's vitelliform macular dystrophy complicated with choroidal neovascularization is rare in children. We report three children from a Malay family of five siblings with Best's vitelliform macular dystrophy, in which two of them subsequently developed choroidal neovascularization. The possible pathogenesis of this rare condition is described and highlighted in this report.
\end{abstract}

Keywords: Best's vitelliform macula dystrophy, choroidal neovascularization, children, Malay

\section{Introduction}

Best's vitelliform macular dystrophy with childhood onset causes a slowly progressive central visual impairment. It is inherited in an autosomal-dominant manner in the majority of cases. Though choroidal neovascularization secondary to Best's vitelliform macular dystrophy is rare, it is known to cause childhood blindness if left untreated. ${ }^{1}$ We report three brothers of a Malay family with Best's vitelliform macular dystrophy, two of whom developed unilateral choroidal neovascularization. Rapid diagnosis and prompt treatment of this condition are essential to prevent significant visual loss in these children.

\section{Case report Case I}

The eldest child was referred to our clinic for bilateral hypermetropia by a private optometrist at the age of 9 years. His cycloplegic refraction was $+7.00 /-0.50 \times 170$ in the right eye and $+7.75 /-0.75 \times 20$ in the left eye. He was prescribed glasses that successfully corrected visual acuity to $6 / 6$ in both eyes. Fundoscopic examination revealed localized elevated foveal lesions with yellowish deposit in both eyes, which were suggestive of Best's vitelliform macular dystrophy. The electrooculogram was abnormal, with Arden ratios of 1.1 in the right eye and 1.3 in the left eye. Family screening revealed that two of his younger brothers had similar fundoscopic findings.

The patient's visual acuity remained stable until the age of 18 years, when he complained of a sudden painless reduction in vision in the right eye, lasting 3 weeks. Visual acuity had deteriorated to 6/36 in the affected eye, while his left eye's vision remained at 6/7.5. Fundoscopic examination revealed evidence of Best's vitelliform macular dystrophy bilaterally, with a submacular hemorrhage in the right eye (Figure 1A and B). Fundus fluorescein angiography of the right eye showed a net of 

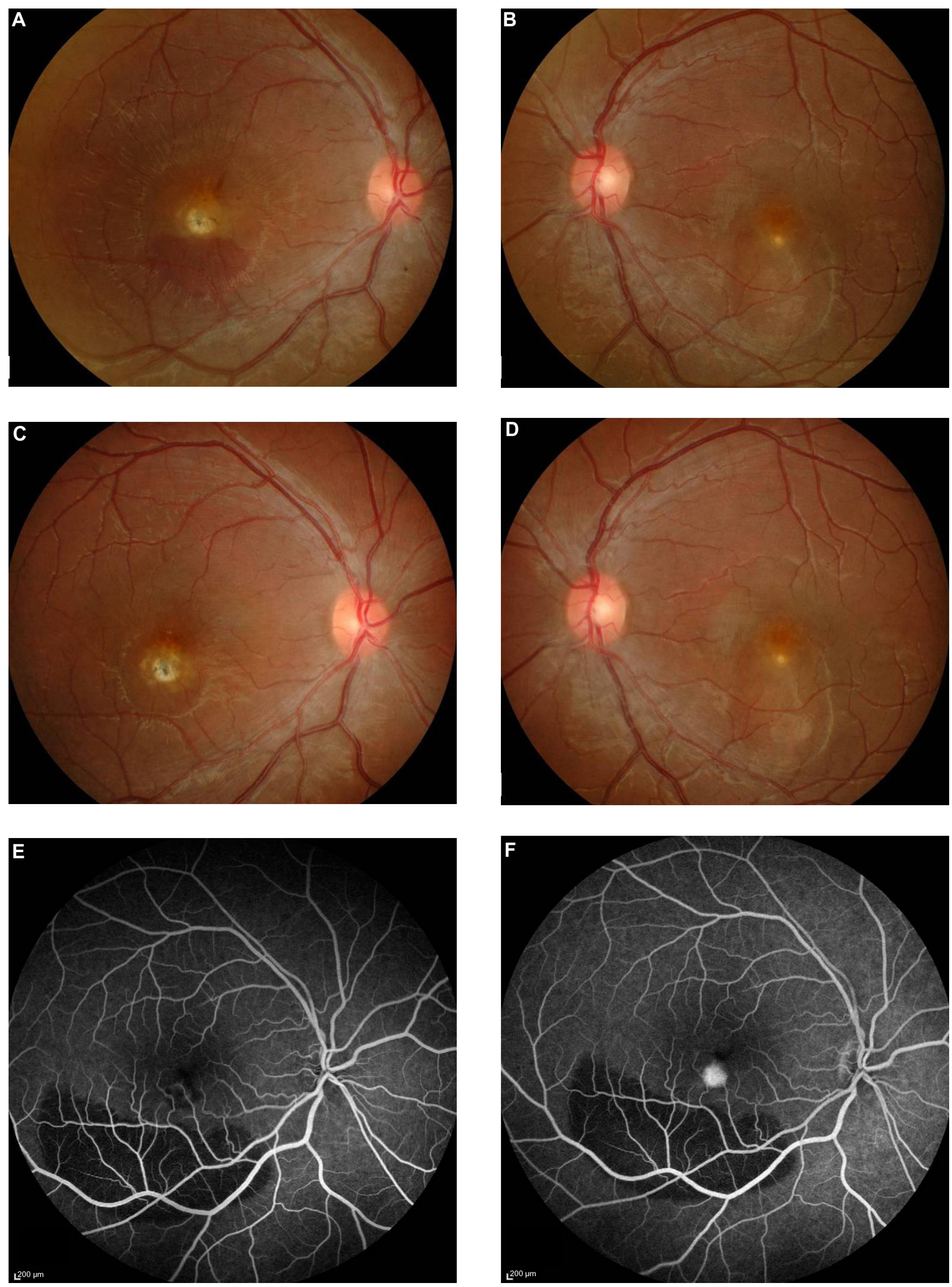

Figure I (Continued) 

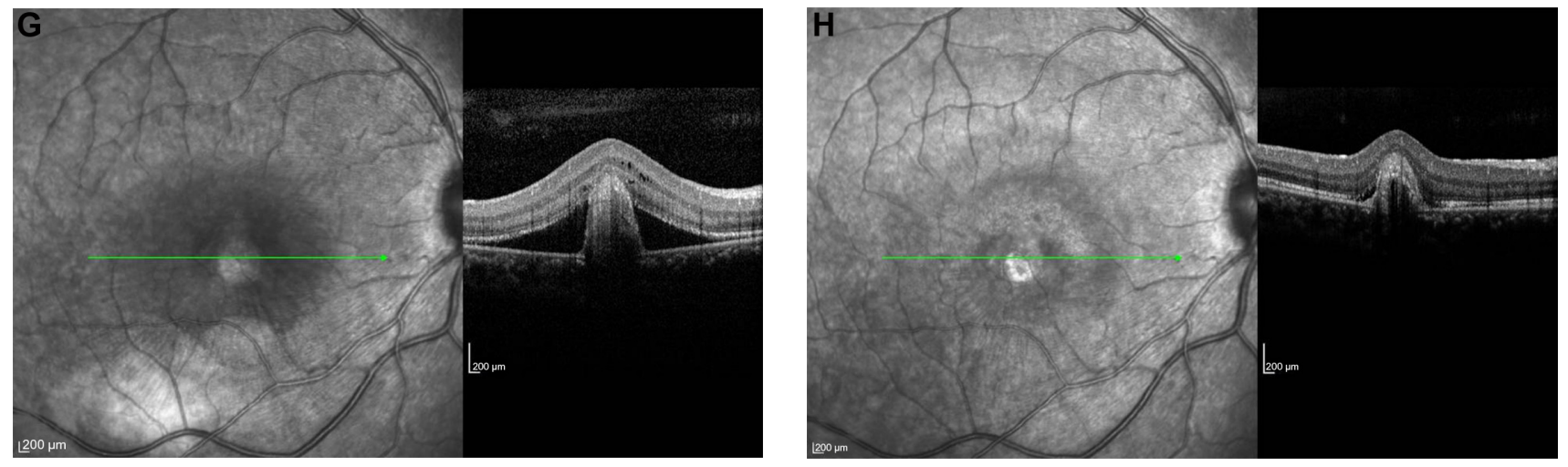

Figure I $(\mathbf{A}-\mathbf{H})$ Case I. Color fundus photograph of the right eye at presentation, showing submacular hemorrhage and a yellowish fibrotic nodule (A). Color fundus photograph of the left eye, showing a dome-shaped elevation at the foveal region with the presence of yellowish deposits (B). Fundoscopy of the right eye, showing resolved subretinal hemorrhage with residual scarring at the foveal region at 2 months posttreatment (C). Fundoscopy of the left eye, showing similar findings to those at presentation (D). Fundus fluorescein angiogram, showing increased hyperfluorescence at the macula, consistent with choroidal neovascularization (E early phase, $\mathbf{F}$ late phase). Optical coherence tomography of the right eye at presentation, showing a subretinal pigment epithelium fibrotic nodule with a subretinal reflection of a subfoveal choroidal neovascularization and surrounding subretinal fluid $(\mathbf{G})$. Optical coherence tomography of the right eye at 2 months posttreatment, showing resolution of the subretinal fluid at the right macula $(\mathbf{H})$. Green lines indicate the cross-section of the macula shown by the adjacent optical coherence tomography image.

increasing hyperfluorescence at the macula, consistent with a choroidal neovascularization (Figure 1E and F). Optical coherence tomography of his right eye revealed subretinal reflection of subfoveal choroidal neovascularization with surrounding subretinal edema (Figure 1G).

The patient was treated with a single dose of intravitreal $1.0 \mathrm{mg}$ ranibizumab under sub-Tenon's local anesthesia. Two months later, his visual acuity improved to 6/12, and fundoscopic examination showed that the subretinal hemorrhage had resolved, with residual scarring at the subfoveal region in the affected eye (Figure 1C and D). These findings were supported by optical coherence tomography imaging (Figure 1H).

He was last evaluated at 9 months posttreatment. His best-corrected visual acuity was $6 / 9$ in the right eye and $6 / 7.5$ in the left eye. Fundoscopic examination remained stable, with no evidence of recurrence in the right eye or new neovascularization in the left eye.

\section{Case 2}

The third child was first examined at 4 years. He was asymptomatic. His best-corrected visual acuity was $6 / 6$ in both eyes. Serial fundoscopy findings revealed signs of Best's vitelliform macular dystrophy. There were no signs of submacular hemorrhage to suggest the presence of choroidal neovascularization (Figure 2A and B). Optical coherence tomography demonstrated minimal signs of subretinal fluid accumulation in both eyes (Figure 2C and D).

\section{Case 3}

The fourth child was diagnosed with Best's vitelliform macular dystrophy at 4 years old after a family eye screening.
At the age of 6 years, he developed a choroidal neovascularization in the right eye (Figure 3A and B), and that was promptly managed. ${ }^{2}$

Currently, his visual acuity is $6 / 6$ in both eyes. Fundoscopic examination (Figure $3 \mathrm{C}$ and $\mathrm{D}$ ) remains stable in both eyes, 3 years after the intravitreal ranibizumab injection in the right eye. No systemic or ocular complications were observed throughout his follow-up.

Detailed clinical presentations of the aforementioned patients and their unaffected siblings are summarized in Table 1. There is no history of consanguinity. Fundoscopic examinations of the second and youngest siblings showed normal findings. Electrooculography was performed in the two older brothers, but was not performed in other siblings, because they were too young at the time of examination. Examination of the parents' eyes was essentially normal, except for the fact that their mother had a hyperpigmented flat scar in her left macula. Genetic analysis was not performed due to financial constraints.

\section{Discussion}

Familial cases of Best's vitelliform macular dystrophy have been described amongst the Spanish, Danish, Italian, French, American, and Chinese. ${ }^{3-7}$ Based on a PubMed literature search, the present study is the first report of familial Best's vitelliform macular dystrophy in individuals of Malay decent, and two of the described children had presented with active choroidal neovascularization.

Zhang et al performed a postmortem examination and described the histopathological findings in two eyes with clinical diagnosis of Best's vitelliform macular dystrophy. 

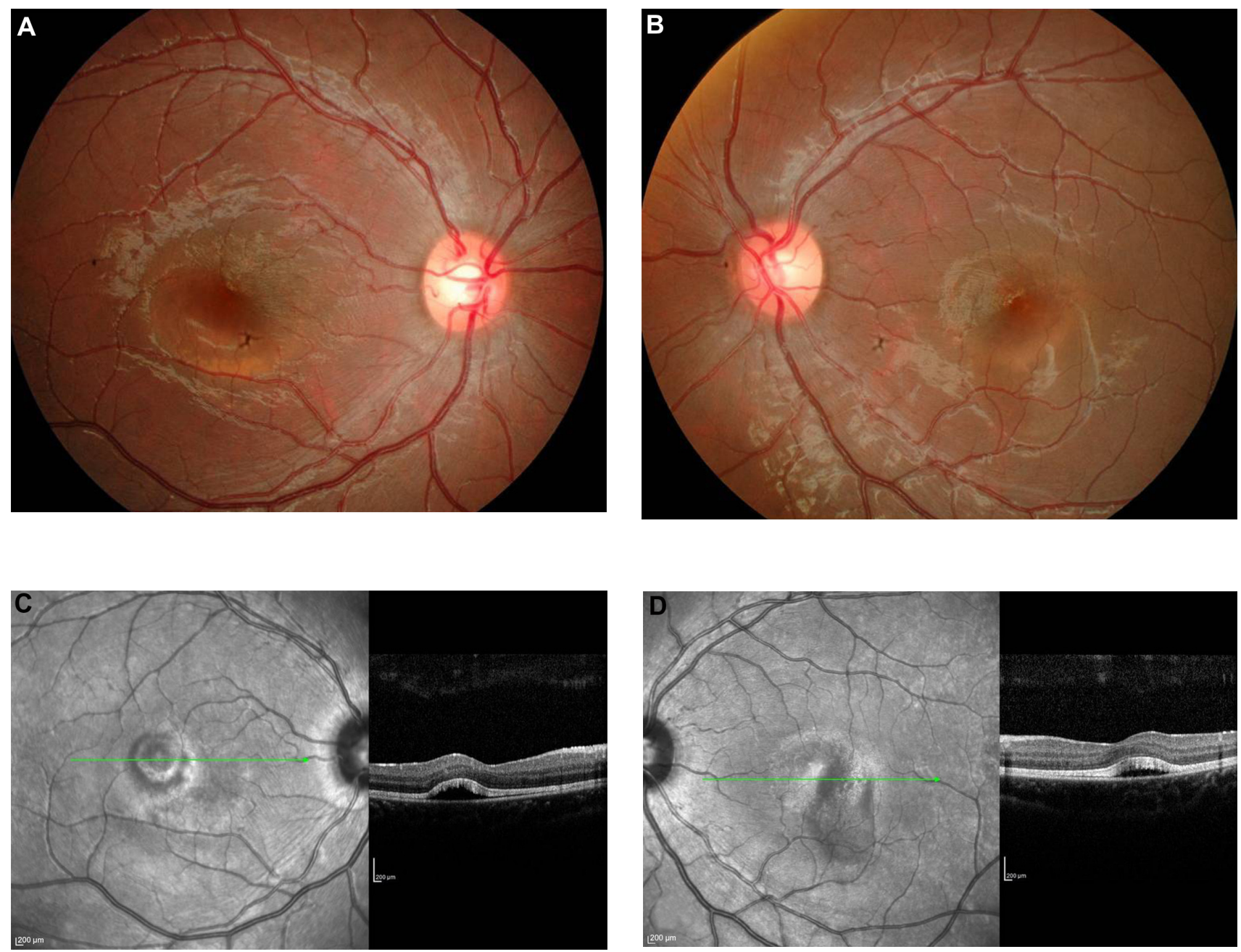

Figure 2 (A-D) Case 2. Color fundus photograph of the right (A) and left (B) eyes showing dome-shaped elevation of the foveal regions, with the presence of yellowish deposits, signifying Best's vitelliform macular dystrophy. Optical coherence tomography of the right (C) and left (D) eye revealed the presence of subretinal fluid at the foveal regions. Green lines indicate the cross-section of the macula shown by the adjacent optical coherence tomography image.

They reported a well-circumscribed area of retinal pigment epithelium (RPE) hyperplasia, accumulation of lipofuscin in the RPE, deposition of granular material in the photoreceptors, macrophages, and drusen. They also observed an area in the region of a large sub-RPE drusen where Bruch's membrane was not intact. ${ }^{8}$

Interestingly, in an animal study, Julien et al found that zinc deficiency in the pigmented eyes of rats yielded an increased lipofuscin accumulation in the RPE, with decreased melanosomes in its microvilli and irregular thickness of Bruch's membrane. ${ }^{9}$ This condition may facilitate the penetration of macrophages from the choroid to the RPE.

RPE dysfunction in Best's vitelliform macular dystrophy causes the accumulation of subretinal fluid, which elevates the retinal layers away from the RPE, making the phagocytosis of the photoreceptor outer segment less likely to occur. The eventual phagocytosis of older photoreceptor outer segment loads the RPE with precursor for lipofuscin. The increased oxidative stress that leads to lipofuscinogenesis increases the amount of free radicals, which further damage the retinal architecture. This postulation probably explains the initiation of choroidal neovascularization formation in Best's vitelliform macular dystrophy.

Querques et al reported that bestrophin mutation did not correlate with disease severity. ${ }^{10}$ Both the age of onset and disease progression were highly variable in patients with the same mutation. Therefore, the variability shown by these three Malay brothers regarding age of onset and disease progression could not be explained. It is difficult to deduce why choroidal neovascularization had developed in these two siblings but not in the other brother, who also showed clinical signs of Best's vitelliform macular dystrophy. Interestingly, we observed that the two siblings who had developed choroidal neovascularization demonstrated larger areas of 

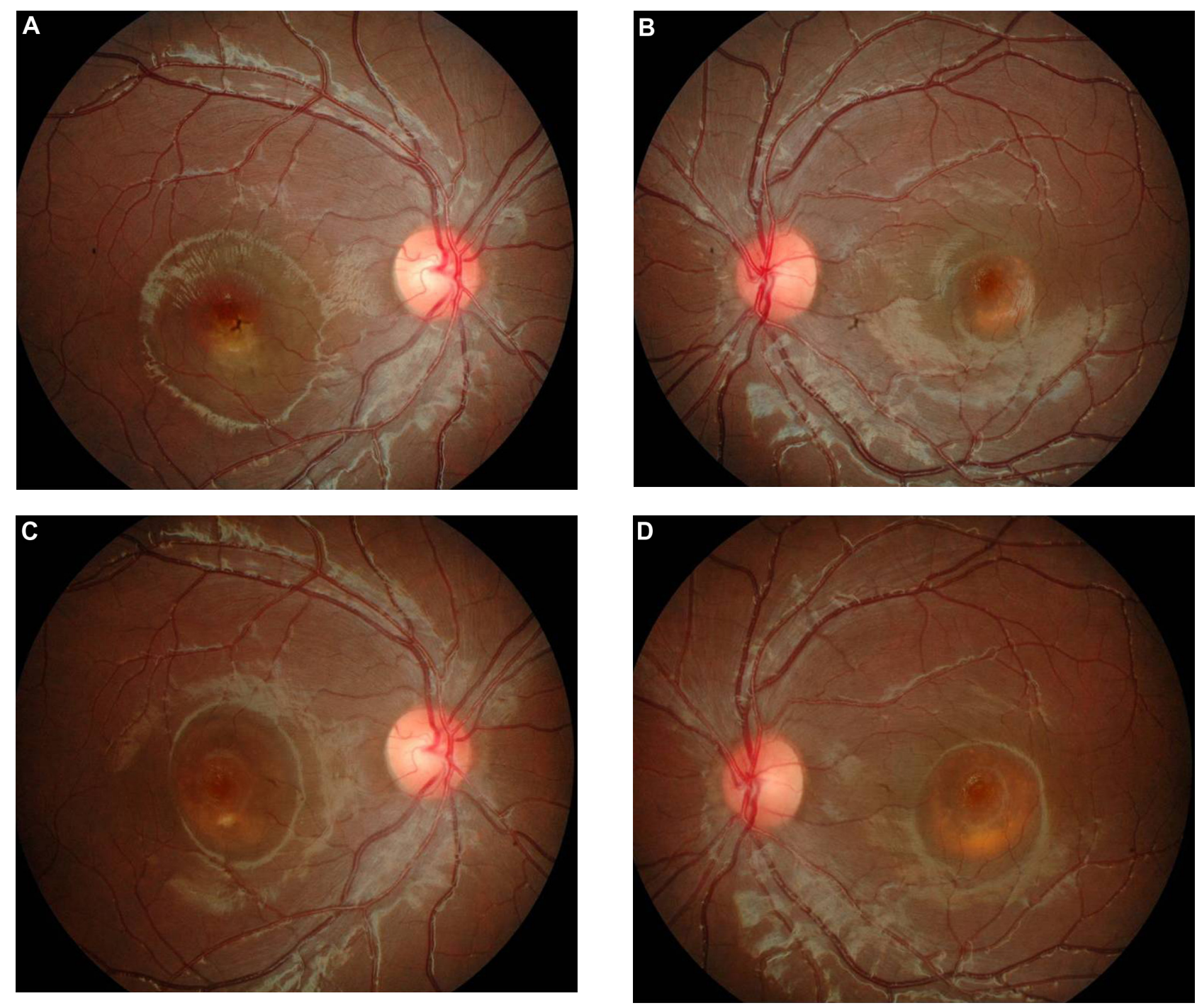

Figure 3 (A-D) Case 3. Color fundus photographs of the fourth child at the time of diagnosis of choroidal neovascularization (A and B). Right fundoscopy at 3 years posttreatment, showing a resolved subfoveal hemorrhage with a residual dome-shaped elevation and yellowish deposits at the foveal region (C). Left fundoscopy at 3 years postpresentation, showing an increase in the size of the dome-shaped elevation, with no sign of a submacular hemorrhage (D).

Table I Clinical summary

\begin{tabular}{|c|c|c|c|c|c|c|c|c|c|c|c|}
\hline \multirow[t]{2}{*}{ Siblings } & \multicolumn{5}{|c|}{ During presentation } & \multicolumn{4}{|c|}{ Complicated by CNV } & \multicolumn{2}{|c|}{ Current status } \\
\hline & $\begin{array}{l}\text { Age, } \\
\text { years }\end{array}$ & Sex & BCVA & Fundoscopy & $\begin{array}{l}\text { Arden } \\
\text { ratio }\end{array}$ & $\begin{array}{l}\text { Affected } \\
\text { eye }\end{array}$ & $\begin{array}{l}\text { Age, } \\
\text { years }\end{array}$ & BCVA & Treatment & $\begin{array}{l}\text { Age, } \\
\text { years }\end{array}$ & BCVA \\
\hline Eldest & 9 & Male & $\begin{array}{l}\text { RE: } 6 / 6 \\
\text { LE: } 6 / 6\end{array}$ & $\begin{array}{l}\text { Bilateral Best's } \\
\text { vitelliform macular } \\
\text { dystrophy }\end{array}$ & $\begin{array}{l}\text { RE: I.I } \\
\text { LE: } 1.3\end{array}$ & Right eye & 18 & $\begin{array}{l}\text { RE: } 6 / 36 \\
\text { LE: } 6 / 7.5\end{array}$ & $\begin{array}{l}\text { Single-dose } \\
\text { intravitreal } \\
\text { ranibizumab } 1.0 \mathrm{mg}\end{array}$ & 19 & $\begin{array}{l}\text { RE: } 6 / 9 \\
\text { LE: } 6 / 7.5\end{array}$ \\
\hline Second & 6 & Male & $\begin{array}{l}\text { RE: } 6 / 6 \\
\text { LE: } 6 / 6\end{array}$ & Normal & $\begin{array}{l}\text { RE: } 1.2 \\
\text { LE: } 1.2\end{array}$ & No & Nil & Nil & Nil & 16 & $\begin{array}{l}\text { RE: } 6 / 6 \\
\text { LE: } 6 / 6\end{array}$ \\
\hline Third & 4 & Male & $\begin{array}{l}\text { RE: } 6 / 9 \\
\text { LE: } 6 / 9\end{array}$ & $\begin{array}{l}\text { Bilateral Best's } \\
\text { vitelliform macular } \\
\text { dystrophy }\end{array}$ & NA & No & Nil & Nil & $\begin{array}{l}\text { Conservative } \\
\text { treatment }\end{array}$ & 14 & $\begin{array}{l}\text { RE: } 6 / 6 \\
\text { LE: } 6 / 6\end{array}$ \\
\hline Fourth & 4 & Male & $\begin{array}{l}\text { RE: } 6 / 9 \\
\text { LE: } 6 / 9\end{array}$ & $\begin{array}{l}\text { Bilateral Best's } \\
\text { vitelliform macular } \\
\text { dystrophy }\end{array}$ & NA & Right eye & 6 & $\begin{array}{l}\text { RE: } 6 / 18 \\
\text { LE: } 6 / 6\end{array}$ & $\begin{array}{l}\text { Single-dose } \\
\text { intravitreal } \\
\text { ranibizumab } 1.0 \mathrm{mg}\end{array}$ & 10 & $\begin{array}{l}\text { RE: } 6 / 6 \\
\text { LE: } 6 / 6\end{array}$ \\
\hline Youngest & 1 & Male & $\begin{array}{l}20 / 100 \\
\text { binocular }\end{array}$ & Normal & NA & No & Nil & Nil & Nil & 7 & $\begin{array}{l}\text { RE: } 6 / 6 \\
\text { LE: } 6 / 6\end{array}$ \\
\hline
\end{tabular}

Abbreviations: RE, right eye; LE, left eye; CNV, choroidal neovascularization; BCVA, best-corrected visual acuity; NA, not available. 
subretinal fluid accumulation and deposits compared to the sibling without choroidal neovascularization formation. We postulate that the severity of RPE dysfunction and an increase in oxidative stress play important roles in the formation of choroidal neovascularization.

Both of the patients responded well to the single dose of intravitreal ranibizumab. The eldest child showed stable visual acuity and fundoscopy findings 9 months after treatment, while the fourth child has not had any recurrence 3 years later. No recurrence or adverse events were noted throughout their follow-up visits. This observation is consistent with an observation by Ruiz-Moreno et al, ${ }^{11}$ where they described an excellent outcome in a 3-year follow-up of a boy who was treated with a single injection of intravitreal ranibizumab for choroidal neovascularization secondary to Best's vitelliform macular dystrophy.

\section{Conclusion}

Choroidal neovascularization secondary to Best's vitelliform macular dystrophy is uncommon in the pediatric community. Two siblings with choroidal neovascularization is particularly unusual. Prompt diagnosis and management of this condition are vital to prevent blindness in these children. A single dose of intravitreal ranibizumab was effective in our patients, but this treatment requires long-term follow-up and monitoring.

\section{Disclosure}

The authors report no conflicts of interest in this work.

\section{References}

1. Leu J, Schrage NF, Degenring RF. Choroidal neovascularisation secondary to Best's disease in a 13-year-old boy treated by intravitreal bevacizumab. Graefes Arch Clin Exp Ophthalmol. 2007;245(11): $1723-1725$.

2. Heidary F, Hitam WH, Ngah NF, George TM, Hashim H, Shatriah I. Intravitreal ranibizumab for choroidal neovascularization in Best's vitelliform macular dystrophy in a 6-year-old boy. J Pediatr Ophthalmol Strabismus. 2011;48 online:e19-e22.

3. Piñeiro-Gallego T, Alvarez M, Pereiro I, et al. Clinical evaluation of two consanguineous families with homozygous mutations in BEST1. Mol Vis. 2011;17:1607-1617.

4. Sodi A, Menchini F, Manitto MP, et al. Ocular phenotypes associated with biallelic mutations in BEST1 in Italian patients. Mol Vis. 2011;17: 3078-3087.

5. Lacassagne E, Dhuez A, Rigaudière F, et al. Phenotypic variability in a French family with a novel mutation in the BEST1 gene causing multifocal best vitelliform macular dystrophy. Mol Vis. 2011;17: 309-322.

6. Iannaccone A, Kerr NC, Kinnick TR, Calzada JI, Stone EM. Autosomal recessive Best vitelliform macular dystrophy: report of a family and management of early-onset neovascular complications. Arch Ophthalmol. 2011;129(2):211-217.

7. Li Y, Wang G, Dong B, et al. A novel mutation of the VMD2 gene in a Chinese family with Best vitelliform macular dystrophy. Ann Acad Med Singapore. 2006;35(6):408-410.

8. Zhang Q, Small KW, Grossniklaus HE. Clinicopathologic findings in Best vitelliform macular dystrophy. Graefes Arch Clin Exp Ophthalmol. 2011;249(5):745-751.

9. Julien S, Biesemeier A, Kokkinou D, Eibl O, Schraermeyer U. Zinc deficiency leads to lipofuscin accumulation in the retinal pigment epithelium of pigmented rats. PLoS One. 2011;6(12):e29245.

10. Querques G, Zerbib J, Santacroce R, et al. Functional and clinical data of Best vitelliform macular dystrophy patients with mutations in the BEST1 gene. Mol Vis. 2009;15:2960-2972.

11. Ruiz-Moreno O, Calvo P, Ferrández B, Torrón C. Long-term outcomes of intravitreal ranibizumab for choroidal neovascularization secondary to Best's disease: 3-year follow-up. Acta Ophthalmol. 2012;90(7): e574-e575.
Clinical Ophthalmology

\section{Publish your work in this journal}

Clinical Ophthalmology is an international, peer-reviewed journal covering all subspecialties within ophthalmology. Key topics include: Optometry; Visual science; Pharmacology and drug therapy in eye diseases; Basic Sciences; Primary and Secondary eye care; Patient Safety and Quality of Care Improvements. This journal is indexed on Submit your manuscript here: http://www.dovepress.com/clinical-ophthalmology-journal

\section{Dovepress}

PubMed Central and CAS, and is the official journal of The Society of Clinical Ophthalmology (SCO). The manuscript management system is completely online and includes a very quick and fair peer-review system, which is all easy to use. Visit http://www.dovepress.com/ testimonials.php to read real quotes from published authors. 